\title{
SIMULAÇ̃̃O NUMÉRICA DO DESASTRE DE ORIGEM NATURAL OCORRIDO EM JANEIRO DE 2011 NO MUNICÍPIO DE NOVA FRIBURGO, RJ, UTILIZANDO O MODELO BRAMS
}

\author{
Marina Aires \\ Universidade Federal Fluminense, Instituto de Geociências, Pós-Graduação em Geografia, \\ Niterói, RJ,Brasil \\ marinageouff@gmail.com
}

Camila Lorrana Freitas Martins

Universidade Federal do Rio de Janeiro, Instituto de Geociências, Pós-Graduação em Geografia,

Rio de Janeiro, RJ, Brasil

camilalorrana@id.uff.br

Gabriela Silva Araujo Cury

Universidade Federal Fluminense, Instituto de Geociências, Geógrafia,

Rio de Janeiro, RJ, Brasil

cury.gabriela@gmail.com

Pedro José Farias Fernandes

Universidade Federal Fluminense, Instituto de Geociências, Doutor em Geografia,

Rio de Janeiro, RJ, Brasil

pj fernandes@id.uff.br

Jorge Luiz Fernandes de Oliveira

Universidade Federal Fluminense, Instituto de Geociências, Professor Titular,

Rio de Janeiro, RJ, Brasil

jorgeo@id.uff.br

\begin{abstract}
RESUMO
O conceito de desastre de origem natural é definido como o produto de um evento de ordem natural inerente à dinâmica da Terra associadas à vulnerabilidade de uma região. Esta vulnerabilidade pode estar associada a fatores naturais, antrópicos ou a uma combinação destes. O ano de 2011 foi marcado pela ocorrência de um desastre de origem natural ocorrido na Região Serrana do Rio de Janeiro (RSRJ) resultando em cerca de 900 mortos e 300 mil pessoas atingidas. Na cidade de Nova Friburgo foram 420 vítimas fatais e cerca de 180 mil pessoas atingidas direta e indiretamente pelo desastre natural $O$ presente artigo analisa o ambiente sinótico e de mesoescala que culminou no desastre natural na cidade de Nova Friburgo. Utilizou-se o modelo atmosférico Brazilian Regional Atmospheric Modelling System (BRAMS) para simular o comportamento da atmosfera no período de 11 a 14 de janeiro de 2011. Verificou-se a partir das imagens do satélite GOES-12, canal Temperatura Realçada, e das simulações do BRAMS, que as chuvas intensas que provocaram os desastres na RSRJ foram geradas pelo deslocamento de uma frente fria que se acoplou a Zona de Convergência de Umidade, organizando a Zona de Convergência do Atlântico Sul.
\end{abstract}

Palavras-chave: Região Serrana do Rio de Janeiro. Modelo BRAMS. Desastre de Origem Natural.

\section{NUMBER SIMULATION OF NATURAL DISASTER OCCURRED IN JANUARY 2011 IN NOVA FRIBURGO, RJ, USING BRAMS MODEL}

\begin{abstract}
The concept of natural disaster is defined as the product of a natural event inherent in the dynamics of the earth associated with the vulnerability of a region. This vulnerability could be associated with natural, anthropogenic factors or a combination of these. The year 2011 was marked by the occurrence of a natural disaster that occurred in the Rio de Janeiro Mountain Region (RSRJ) resulting in about 900 deaths and 300,000 people affected. In the city of Nova Friburgo there were 420 fatalities and about 180 thousand people directly and indirectly affected by the natural disaster. This article analyzes the synoptic and mesoscale
\end{abstract}


environment that culminated in the natural disaster in the city of Nova Friburgo. The Brazilian Regional Atmospheric Modeling System (BRAMS) atmospheric model was used to simulate the behavior of the atmosphere from January 11 to 14,2011 . It was verified from GOES-12 satellite images, Enhanced Temperature channel, and BRAMS simulations that the heavy rains that caused the RSRJ disasters were generated by the displacement of a cold front that coupled the Moist Convergence Zone, organizing the South Atlantic Convergence Zone.

Keywords: Mountainous Region of Rio de Janeiro. BRAMS model. Natural Disaster.

\section{INTRODUÇÃO}

Os desastres de origem natural, durante as últimas décadas, estão cada vez mais presentes em nosso cotidiano. O número crescente de pesquisas relacionadas ao tema, bem como a sua relação com as mudanças climáticas, a frequência e a intensidade maior dos desastres e com a disseminação de notícias veiculadas pelas mídias, corrobora para que esse assunto seja mais abordado pelo público em geral.

Segundo o Ministério da Integração Nacional (2011, o conceito de desastre pode ser definido como o "resultado de eventos adversos, naturais ou provocados pelo homem, sobre um ecossistema vulnerável, causando danos humanos, materiais e ambientais e consequentes prejuízos econômicos e sociais." Os desastres estão, em um primeiro momento, relacionados aos fenômenos atmosféricos, oceânicos ou geomorfológicos/geológicos como os terremotos, tsunamis, erupções vulcânicas, furacões, secas, chuvas extremas (Amaral et al., 2009).

Os desastres são classificados de acordo com a natureza do fenômeno que o desencadeou e, de acordo com Castro (1998), podem ser de três classes: os naturais, os humanos e os mistos, onde a intervenção das atividades antrópicas é a principal questão. Marcelino (2007) ressalta que a análise feita a partir de um desastre não deveria estar focada no processo e sim no que causa o fenômeno. Os desastres naturais são aqueles que são desencadeados pela intervenção de um fenômeno natural, ao passo que os desastres antrópicos são aqueles oriundos pela ação humana (Ministério da Integração Nacional, 2011 Marcelino, 2007).

Tobin et al. (2017) categorizaram os desastres de origem natural, seguindo duas tipologias, a primeira: focalizada na gênese de seus fenômenos desencadeadores, como meteorológico (ciclones tropicais, furacões e tufões, tempestades, tornados, raios, vendavais, tempestades de granizo, gelo ou neve, ondas de frio) ;geológico (vulcanismo, tsnunamis, escorregamentos de massa, subsidência); hidrológico (enchentes, secas, fogo) e extraterrestres (meteoritos) e a segunda tipologia baseada na diferenciação das características dos desastres, como a frequência, duração, extensão, velocidade, dispersão e o comportamento.

Com relação aos desastres naturais a nível mundial, Kobiyama et al. (2006) ressalta que o número de registros de desastres cresce consideravelmente, e tem como principais causas o aumento populacional, a ocupação desordenada dos solos urbanos e ao intenso processo de industrialização e os fatores que corroboram para o desencadeamento de desastres nas cidades são a impermeabilização dos solos, as ocupações desordenadas, o desmatamento, o assoreamento dos corpos de água, a concentração de calor e a poluição ambiental.

Segundo o The Emergency International Disaster Database (EM -DAT, 2019), que está relacionado ao Centre for Research on the Epidemiology of Disasters (CRED), nos últimos 20 anos de dados (1998 - 2018), a categoria do desastre natural mais registrado foi o hidrológico, seguido do meteorológico, geofísico e biológico. Com relação à classificação dos tipos de desastres os escorregamentos foram os mais registrados, seguidos de tempestades, outros tipos de desastres, epidemias, secas e terremotos.

Marcelino (2007) ressalta que dentre os continentes que apresentam os maiores registros de desastres de origem natural, no período entre 1900 a 2006, destacam-se a Ásia e as Américas, onde tempestades, inundações e terremotos respectivamente são os desastres mais expressivos. Segundo 
o EM-DAT (2007), os desastres de origem natural ocorrem em países em desenvolvimento devido à ocupação do solo indiscriminada em áreas impróprias, a falta de políticas públicas urbanas e ambientais e a falta de utilização de técnicas de estabilização de encostas e taludes. O Brasil, que está inserido no continente americano, segundo o Anuário Brasileiro de Desastres Naturais (2011) indica que no ano de 2011, os desastres tiveram impacto significativo na população brasileira. Foram registrados 795 desastres naturais, que acometeram, cerca de 1.100 pessoas e afetaram cerca de 12.500.000 pessoas e 2.370 municípios foram atingidos pelos eventos, sendo que $65 \%$ destes foram de origem hidrológica.

Segundo o Anuário Brasileiro de Desastres Naturais (2011), a Região Sudeste registrou a maior percentagem de óbitos, grande parte destes estão relacionados ao evento extremo que aconteceu na Região Serrana do Estado do Rio de Janeiro (RSRJ), em janeiro de 2011, cerca de $88 \%$. Os movimentos de terra foram o mais frequentes nas Regiões Sul e Sudeste do Brasil.

A RSRJ é composta pelos municípios de Cantagalo, Carmo, Cordeiro, Bom Jardim, Duas Barras, Nova Friburgo, Sumidouro, Santa Maria Madalena, São Sebastião do Alto, Trajano de Morais, Petrópolis, São José do Vale do Rio Preto, Teresópolis e Macuco. Segundo Dourado et al. (2012) foram sete cidades atingidas diretamente pelo desastre, no período de 10 a 15 de janeiro de 2011, porém Nova Friburgo, Teresópolis e Petrópolis foram as mais devastadas por uma série de movimentos de massa. A Organização das Nações Unidas (ONU) considerou o desastre da RSRJ como um dos 10 piores deslizamentos do mundo dos últimos 111 anos (PORTAL G1, 2011b).

Um dos fenômenos meteorológicos que atuam na área nos meses de verão é a Zona de Convergência de Umidade (ZCOU). Este conceito foi introduzido pelo Grupo de Previsão de Tempo e Estudos Climáticos (GPT-CPTEC) do Instituto Nacional de Pesquisas Espaciais e foi criado para explicar as variações no padrão da Zona de Convergência do Atlântico Sul (ZCAS), a partir de observações realizadas no cotidiano (Pallotta e Nakazato, 2010; Sacramento et al., 2010). Pallotta e Nakazato (2010) ressaltam que ambas as zonas apresentam semelhanças com relação à convergência de umidade, que são marcadas por nebulosidade e precipitação, mas apresentam diferenças nos padrões de escoamento em médios e baixos níveis, "que desfavorecem a persistência e organização da banda de nebulosidade/precipitação, caracterizando assim uma ZCOU ao invés de ZCAS" (Pallotta e Nakazato, 2010, pág. 2 ).

Os modelos numéricos são ferramentas de análise científica, que utilizam equações matemáticas e princípios físicos, sendo utilizados de forma prognóstica, ou seja, para prever o comportamento futuro de um sistema ou utilizados de forma diagnóstica, quando a partir de dados observados, pode-se analisar fenômenos que ocorreram no passado ( $\mathrm{LYNCH}, 2007)$. A modelagem numérica da atmosfera é utilizada para simular fenômenos atmosféricos de diferentes escalas espaciais e temporais.

O desastre de origem natural de grandes proporções, ocorrido na RSRJ, causado por áreas de instabilidade caracterizadas como ZCOU e, posteriormente, como ZCAS, devido ao acoplamento de um sistema frontal, motivou a realização do presente trabalho. $O$ objetivo do presente artigo é analisar o ambiente sinótico e de mesoescala, associando os resultados ao ambiente antrópico, como forma de compreender as causas que deflagraram o desastre de origem natural em Nova Friburgo, utilizando o modelo Brazilian Regional Atmospheric Modelling System (BRAMS).

\section{ÁREA DE ESTUDO}

O município de Nova Friburgo está localizado no Estado do Rio de Janeiro, ressalta-se que na divisão política e administrativa do Estado, a denominação "Região Serrana" não existe, a denominação oficial realizada pelo Instituto Brasileiro de Geografia e Estatística é Região Centro Fluminense (IBGE, 2019). O município está localizado entre os paralelos $21^{\circ} 40^{\prime} \mathrm{S}$ e $22^{\circ} 35^{\prime} \mathrm{S}$ e os meridianos $41^{\circ} 40^{\prime} \mathrm{W}$ e $43^{\circ} 25^{\prime} \mathrm{W}$, com altitude de $846 \mathrm{~m}$ (Figura 1) e tem área total de $935.429 \mathrm{~km}^{2}$. Segundo o IBGE, a partir do Censo de 2010, a população estimada do município era de 182.082 habitantes. Possui 8 distritos, Centro; Riograndina; Campo do Coelho; Amparo; Lumiar; Conselheiro Paulino; São Pedro da Serra e Mury.

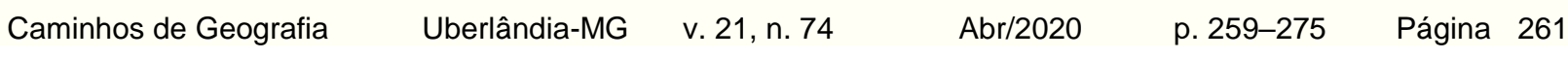


Figura 1 - Localização da área de estudo.

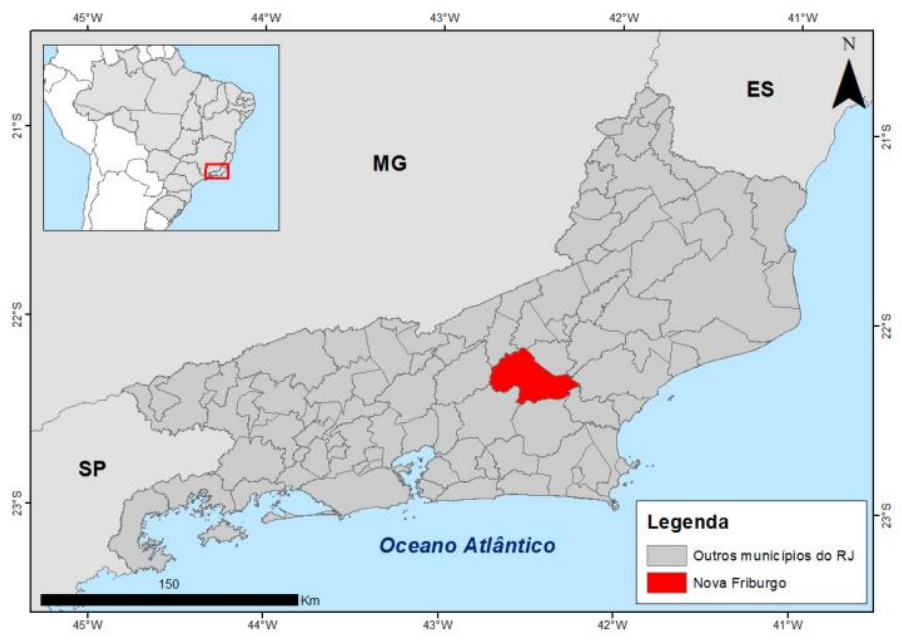

O município se estabeleceu a partir de uma área indígena, conhecida como "sertão ocupado por várias nações dos índios brabos". Quando os europeus chegaram à região foram atraídos pela cafeicultura, que se expandiu pelos territórios. A partir do século XIX, com a vinda da Família Real para o Rio de Janeiro, houve a intensificação da colonização do interior do país e Dom João VI autorizou Cantão de Friburgo, na Suíça, a estabelecer uma colônia na Fazenda do Morro Queimado, localizada no Distrito de Cantagalo. Essa colônia foi denominada de Nova Friburgo, por conta dos primeiros colonizadores e a partir de meados do século $\mathrm{XX}$, os suíços desembarcaram na região (PREFEITURA DE NOVA FRIBURGO, 2014; IBGE, 2019).

A partir de então Nova Friburgo crescia, tanto no meio urbano quanto no meio rural, devido ao comércio local, composto por alfaiatarias, sapatarias, oficinas de fabricação de ferramentas, cervejas e café. Em 1935, houve a inauguração de uma estação de passageiros e, posteriormente houve a instalação da Fábrica de Ferragens Hans Gaiser. A cidade se transformava em um pólo comercial e industrial do Centro Norte Fluminense e consequentemente houve migração da população dos outros municípios para Nova Friburgo (PREFEITURA DE NOVA FRIBURGO, 2014; IBGE, 2019).

Em 1960, a cidade já tinha cerca de 70 mil habitantes, houve a instalação de novas fábricas do setor de metalurgia, mecânica e têxteis. Surgiram nessa época as iniciativas voltadas para o planejamento urbano e relações internacionais com o governo suíço para a consolidação de Nova Friburgo como a "Suíça Brasileira". A partir dessas relações, houve a construção da Queijaria-Escola e incentivos para a preservação da história dos moradores e das famílias de Nova Friburgo. Atualmente, a cidade é responsável por cerca de $25 \%$ da produção nacional de lingerie, onde se destacam os distritos de Olaria e Conselheiro Paulino, e nesse distrito encontram-se instaladas indústrias do setor metalúrgico e mecânico. A agricultura e a psicultura têm destaque no município, por conta da produção de frutas, verduras, legumes, floricultura e a produção de trutas. Outra atividade que movimenta a economia é o turismo, com destaque para o clima, paisagens paradisíacas e o turismo gastronômico e 0 de compras (PREFEITURA DE NOVA FRIBURGO, 2014; IBGE, 2019).

Segundo O IBGE (2019), a densidade demográfica registrada em Nova Friburgo era de 195,07 habitantes $/ \mathrm{km}^{2}$ e segundo o Tribunal de Contas Estadual (TCE, 2011, pag.:8) "a taxa de urbanização correspondia a $87 \%$ da população. Em comparação com a década anterior, a população do município aumentou $5 \%$, o $67^{\circ}$ maior crescimento do estado."

Tratando-se dos aspectos ambientais de Nova Friburgo, segundo estudos realizados por Dantas et al. (2001), a Região Serrana apresenta relevo montanhoso de alta declividade, com ocorrência de alta susceptibilidade a processos de erosão e movimentos de massa, sendo uma área de Planaltos e Escarpas da Serra do Mar. Apresenta também vertentes retilíneas a côncavas, com escarpas, com amplitudes topográficas que variam de 350 a 600 metros. Predominam Cambissolos e os Latossolos Vermelho-Amarelo álicos, solos pouco espessos e com baixa fertilidade. Segundo Dantas et al. (2001), os solos são inadequados para a urbanização, agricultura e pecuária e a partir da análise geomorfológica, geológica e pedogenética, o município apresenta um alto potencial à ocorrência de movimentos de massa. A vegetação é composta por Florestas Ombrófilas (Densa, Mista e Aberta) e 
insere-se Nova Friburgo no Bioma Mata Atlântica (IESB e UFRJ, 2007). O município é banhado pelas bacias hidrográficas do Rio Grande, Bengalas e Macaé.

Dantas et al. (2001) descreve o clima de Nova Friburgo como sendo úmido e ameno devido à barreira física, efeito orográfico, natural da região. A Figura 2 apresenta o gráfico das temperaturas máximas e mínimas da estação meteorológica do município de Nova Friburgo do Instituto Nacional de Meteorologia (INMET), utilizando dados da última Normal Climatológica, 1961-1990.

Figura 2 - Gráfico Comparativo de Temperaturas Mensais Máximas e Mínimas (1961-1990).

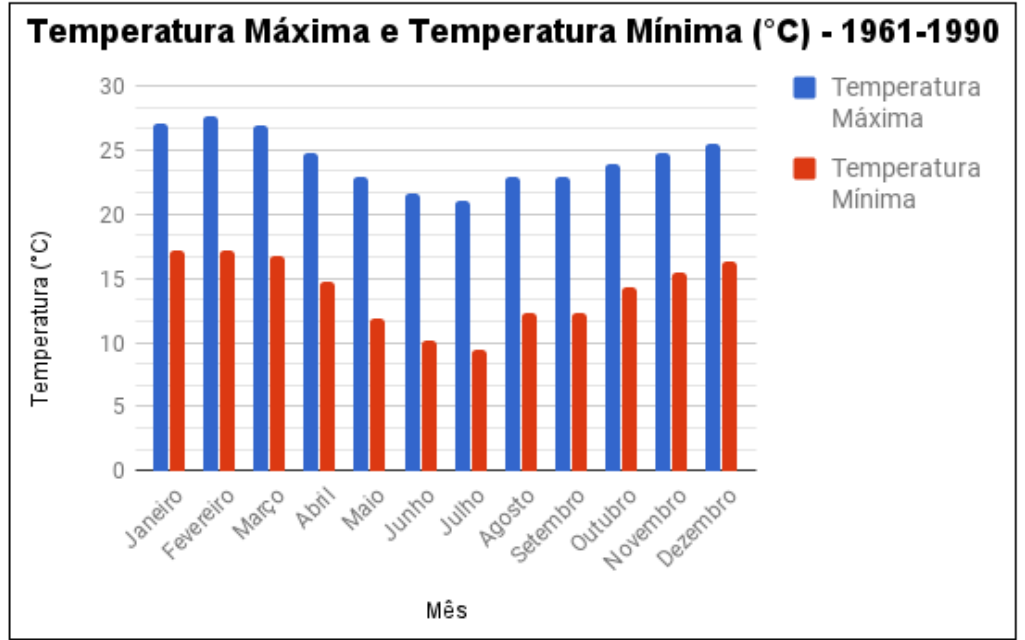

Fonte - Instituto Nacional de Meteorologia (1990).

A maior temperatura ocorre no mês de fevereiro, $27,6^{\circ} \mathrm{C}$, e a menor temperatura é a no mês de julho, $9,5^{\circ} \mathrm{C}$. Segundo a Empresa Brasileira de Pesquisa Agropecuária (EMBRAPA, 2001) o clima da região é caracterizado como Cwb na classificação climática de Köppen. Esta classificação corresponde a um Clima Subtropical de Altitude com um inverno seco e um verão ameno. A Figura 3 mostra os valores de precipitação acumulada na estação meteorológica de Nova Friburgo/RJ do INMET.

Figura 3 - Valores de Precipitação Acumulada $(\mathrm{mm})$ na estação meteorológica de Nova Friburgo/RJ (1961-1990).

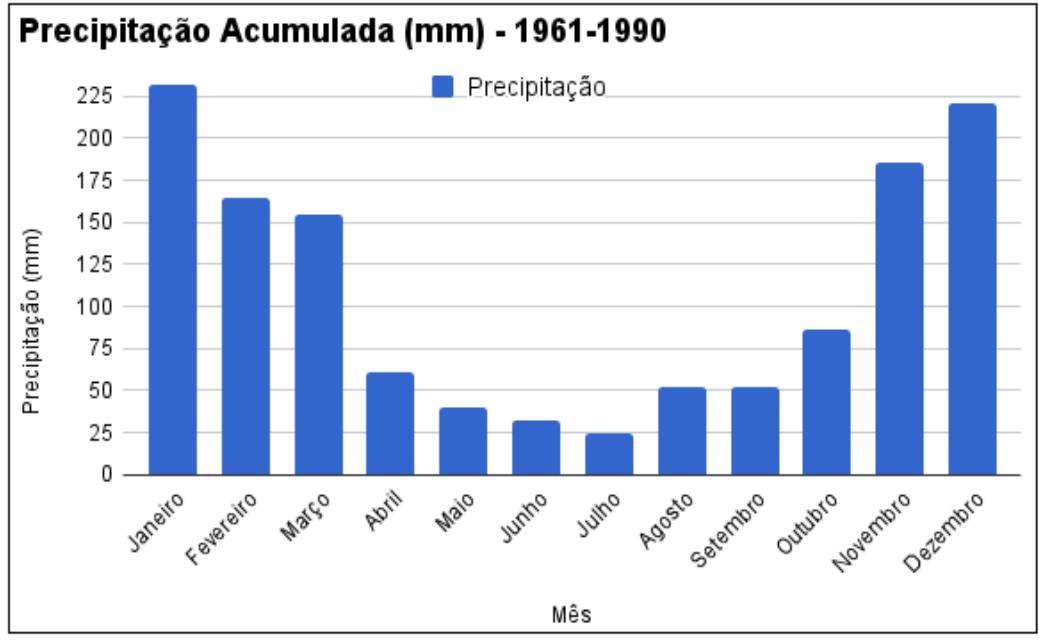

Fonte - Instituto Nacional de Meteorologia (1990). 
Observa-se que nos meses de novembro a janeiro ocorre o período de chuvas mais intensas no município, porém ainda ocorrem chuvas nos meses de fevereiro e março. Já nos meses de junho a agosto (inverno), há o menor índice pluviométrico do município.

\section{O MEGADESASTRE DA REGIÃO SERRANA EM JANEIRO DE 2011}

O desastre de origem natural ocorrido na RSRJ, na tarde e noite do dia 11 e na madrugada do dia 12 de janeiro de 2011, foi deflagrado pela influência de uma zona de convergência de umidade, provocando chuvas intensas, enchentes no sistema de drenagem e inúmeros deslizamentos de terra em 10 municípios da região, porém sete municípios foram os mais afetados: Nova Friburgo, Teresópolis, Petrópolis, Sumidouro, São José do Vale do Rio Preto, Bom Jardim e Areal (Pereira et al., 2013). Segundo Banco Mundial (2012) foram registrados 166 milímetros de chuva em Nova Friburgo provocando danos consideráveis no município (Figura 4).

Figura 4 - Fotografias do desastre na cidade de Nova Friburgo.
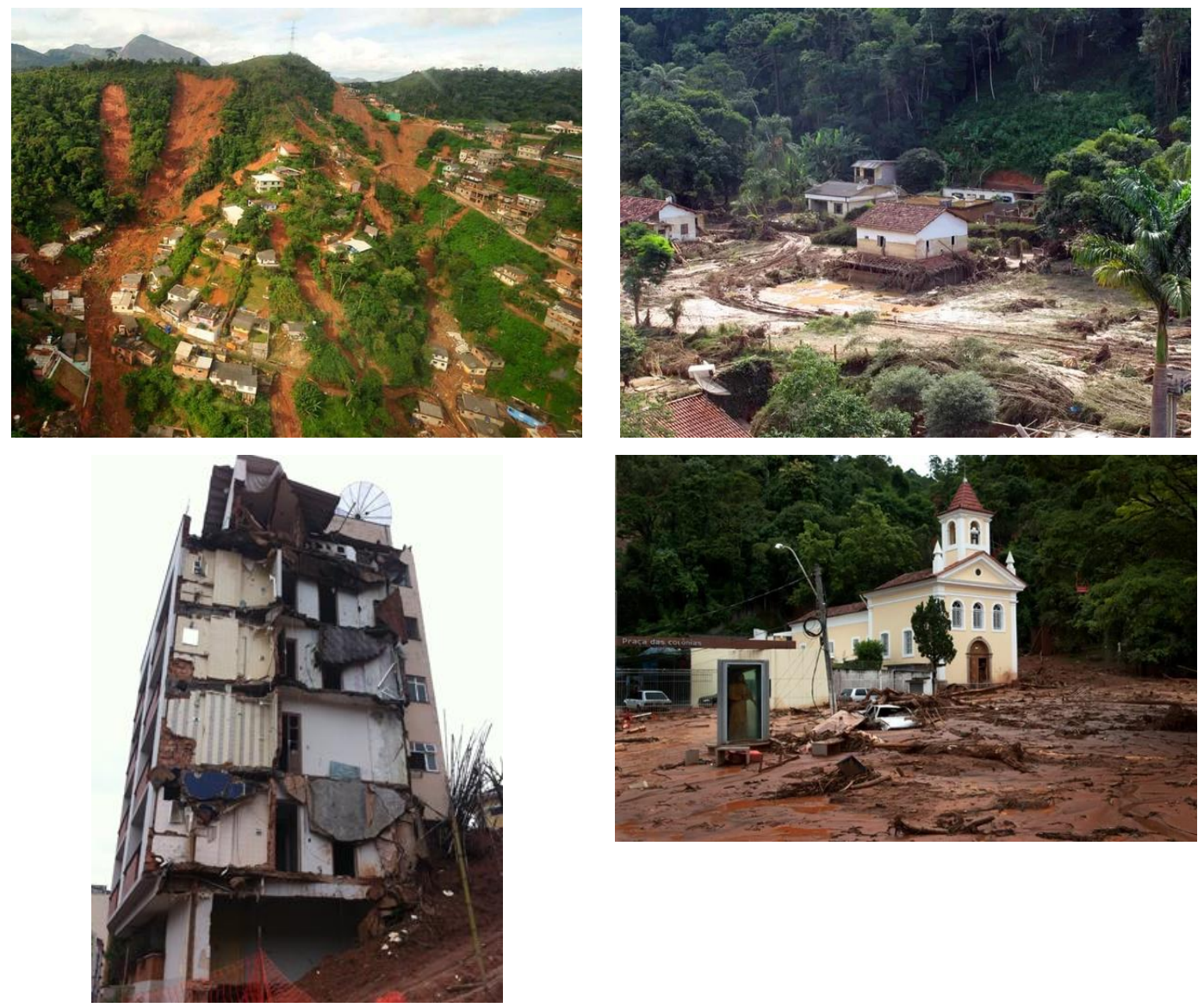

Fonte - Portal G1 (2011a).

Os municípios de Areal, Bom Jardim, Nova Friburgo, São José do Vale do Rio Preto, Sumidouro, Petrópolis e Teresópolis decretaram estado de calamidade pública, sem contar os municípios de Santa Maria Madalena, Sapucaia, Paraíba do Sul, São Sebastião do Alto, Três Rios, Cordeiro, Carmo, Macuco e Cantagalo que foram afetados. Segundo o Banco Mundial (2012) o evento ocorrido foi classificado como o pior desastre registrado na história do Brasil, que acometeu cerca de 900 
pessoas e afetaram aproximadamente 300 mil pessoas. Banco Mundial (2012) afirma: "a escala do desastre pode ser representada pelo número de funcionários envolvidos no processo de resposta. Mais de mil homens de diferentes organizações (Defesa Civil, Prefeituras, Governos Estaduais, Força Nacional de Segurança Pública, Forças Armadas) foram destacados para atuar na região nas operações pós-desastre" (Figura 5).

Figura 5 - Membros da força tarefa que foi montada para atender os municípios afetados pelo desastre.
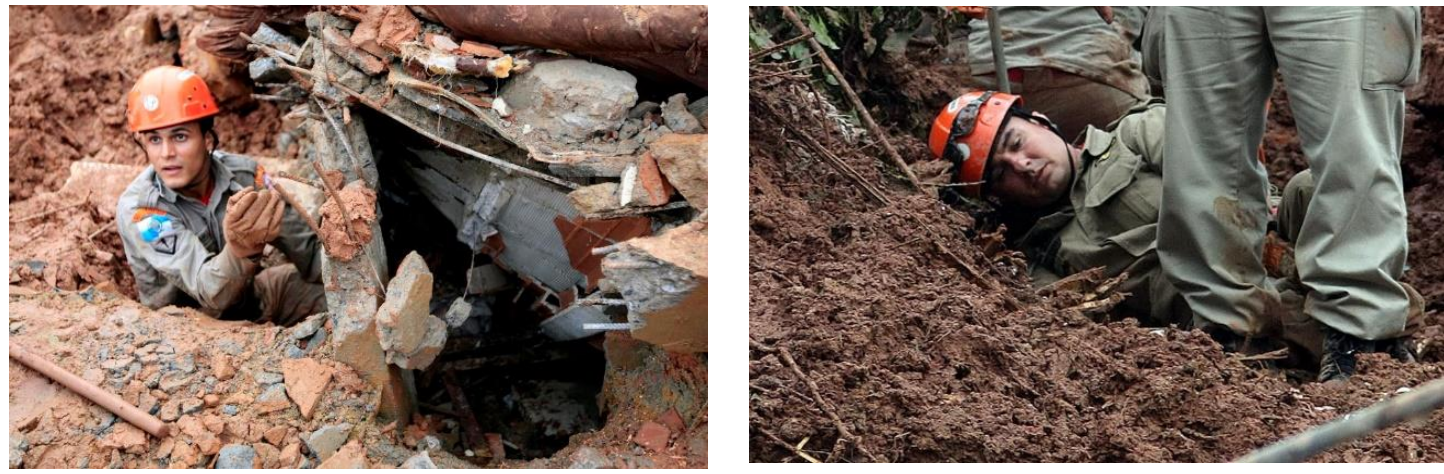

Fonte - Jornal O Estadão (2011).

Banco Mundial (2012) ressalta que ocorreram enxurradas que arrastaram árvores, rochas e edificações, soterrando pessoas residentes nestes locais. O número de mortos é incerto para a RSRJ, contabilizações realizadas pela Secretaria Estadual de Saúde e Defesa Civil é de 916 mortes, sendo 426 registros em Nova Friburgo; o Governo do Estado do Rio de Janeiro indica que 918 pessoas morreram no desastre; já o Observatório de Clima e Saúde, que é ligado à Fundação Osvaldo Cruz (FIOCRUZ), contabilizou 428 mortos na cidade de Nova Friburgo. Milhares de famílias ficaram desabrigadas. O ICICT (2011) mostra que o número de desabrigados e desalojados, para o mês de janeiro de 2011, foi de aproximadamente 13 mil pessoas.

O Centro de Pesquisas e Estudos de Desastres - CEPED (2012) ressalta que além dos problemas relacionados às enchentes e aos deslizamentos de terra, a população sofreu ainda com uma epidemia de leptospirose. Dados do ICICT (2011) apontam que a taxa de leptospirose chegou a $1.2 \%$, no mês de janeiro de 2011. A cidade de Nova Friburgo reportou, segundo o Banco Mundial (2012), 180 mil afetados, sendo 60\% da população atingida pelo evento extremo.

Banco Mundial (2012) aponta que: "Com relação às perdas e danos, estimativas do Banco Mundial apontam para custos totais da ordem de $\mathrm{R} \$ 4.78$ bilhões. Dentre estes custos, aproximadamente $\mathrm{R} \$$ 3.15 bilhões correspondem ao setor público e $\mathrm{R} \$ 1.62$ bilhões são de propriedade privada. Em relação aos prejuízos, o setor habitacional foi o que registrou custos privados mais relevantes $(R \$ 647$ milhões). Os setores sociais foram os que mais sustentaram perdas e danos, com um custo total estimado em $R \$ 2.69$ bilhões. Em segundo lugar, o setor de infraestruturas foi impactado em cerca de $R \$ 1$ bilhão. Os setores produtivos tiveram custos diretos e indiretos estimados em $R \$ 896$ milhões, enquanto os impactos ambientais foram estimados em $\mathrm{R} \$ 71.4$ milhões."

\section{MODELO BRAMS}

O BRAMS é um modelo regional que foi desenvolvido a partir do Regional Atmospheric Modelling System (RAMS), um modelo de circulação prognóstico desenvolvido na Universidade do Colorado, seguindo o modelo de mesoescala desenvolvido por Pielke (1974) e o modelo de nuvens de Trípoli e Cotton (1980). Fundamentado na integração de equações diferenciais clássicas, como a conservação de massa, energia e momentum, com referência a um sistema de coordenadas que engloba o terreno. 
O modelo BRAMS é resultado de um projeto de pesquisa desenvolvido no início dos anos 2000 e foi patrocinado pela Financiadora de Estudos e Projetos (FINEP), cujo objetivo principal era adaptar o RAMS para os trópicos, no intuito do modelo ser utilizado nos centros de pesquisa e de previsão de tempo no Brasil. O BRAMS foi aperfeiçoado durante o doutorado dos pesquisadores Saulo Ribeiro de Freitas e Karla Longo no Instituto de Física da Universidade de São Paulo e melhorias adicionais foram implementadas no NASA Ames Research Center, com colaboração do pesquisador Robert Charfield.

As "novidades" do BRAMS estão na parametrização convectiva, elaborado por Grell e Devenyi (2002), e na parametrização de Cumulus rasos, elaborado por Souza (1999), o que torna o BRAMS mais confiável para ser utilizado para estudos no Brasil. Portanto, ao modelo RAMS foi adicionada a letra B de Brazilian (Alves, 2006).

As equações utilizadas no modelo são descritas por Tripoli e Cotton (1980;1982) e por Pielke (1984) e utilizam o conceito de atmosfera não hidrostática, ou seja, que permite a descrição de processos físicos cuja velocidade vertical é intensa. O BRAMS resolve numericamente as equações governantes da atmosfera, tais como a Segunda Lei de Newton ou Conservação de Momentum; a Primeira Lei da Termodinâmica ou a Conservação da Energia Térmica e a Equação da Continuidade ou a Conservação de Massa (VILHENA, 2010).

\section{METODOLOGIA}

Para gerar as análises e previsões com o modelo BRAMS utilizou-se os dados diários das Reanálises (R1) (Kalnay et al., 1996), disponibilizadas de forma gratuita pelo National Centers for Environmental Prediction (NCEP) e pelo National Center for Atmospheric Research (NCAR), nos horários das 00, 06, 12 e 18 Z. Foram utilizadas imagens do satélite GOES-12, no canal infravermelho com temperatura realçada. As imagens são disponibilizadas pela Divisão de Satélites Ambientais (DSA) do INPE, bem como as análises sinóticas disponibilizadas pelo CPTEC. Na presente pesquisa foram utilizados dados para os dias 11 a 14 de janeiro de 2011.

Para simular as condições sinóticas e de mesoescala do período supracitada, realizou-se um experimento com o modelo BRAMS 4.3. O modelo foi inicializado com a R1 do NCEP/NCAR, com o tempo de integração de 96 horas, porém utilizou-se os 2 dias em que ocorreu o Mega desastre da RSRJ (11 e 12 de janeiro de 2011). Utilizou-se a relaxação Newtoniana, para assimilação dos dados, no centro, nas laterais e no topo do domínio. Optou-se pela utilização de 1 grade com resoluções de 40 x $40 \mathrm{~km}$ (Grade 1), centradas nas coordenadas $22^{\circ} 17^{\prime} 00^{\prime \prime} \mathrm{S}$ e $42^{\circ} 32^{\prime} 12^{\prime \prime} \mathrm{W}$ e nudging de 21600 na fronteira lateral, 43200 no centro e 21600 no topo. Com o passo de tempo utilizado e o espaçamento entre os pontos garantiu-se a estabilidade do modelo.

A Tabela 1 apresenta as configurações das grades utilizadas no BRAMS. O modelo gerou os campos de umidade relativa e vento. As Figuras referentes aos campos simulados com o BRAMS foram elaboradas com o software Grid Analysis and Display System (GrADS) (Doty, 1995).

Tabela 1 - Resumo das Configurações das Grades.

\begin{tabular}{l|c|c|c|c}
\hline & № Pontos em X & № Pontos em Y & $\Delta \mathrm{x}=\Delta \mathrm{y}(\mathrm{Km})$ & $\Delta \mathrm{t}(\mathrm{s})$ \\
\hline Grade 1 & 35 & 35 & 40 & 60 \\
\hline Grade 2 & 78 & 78 & 10 & 15 \\
\hline Grade 3 & 34 & 34 & 2,5 & 3,7 \\
\hline
\end{tabular}

As fases de processamento do BRAMS estão descritas na Figura 6. Na fase de pré-processamento baixam-se as reanálises do NCEP/NCAR ou do CPTEC/INPE, as quais contêm dados de escala global, com informações globais. No passo seguinte, define-se as condições iniciais e de contorno para a área de interesse, tais como a data, as coordenadas geográficas, o número de grades a serem utilizadas, os tipos de topografia, solo, vegetação, bem como os tipos de parametrizações a 
serem utilizadas, para que seja inicializado o modelo; na fase de processamento, o modelo é executado, com as condições fornecidas pelo usuário, gerando arquivos de análise, nos quais os dados da simulação estão contidos; e na fase do pós processamento, são obtidos os resultados da simulação visualizados com o auxílio do software GrADS.

Figura 6 - Fases de processamento do modelo BRAMS.

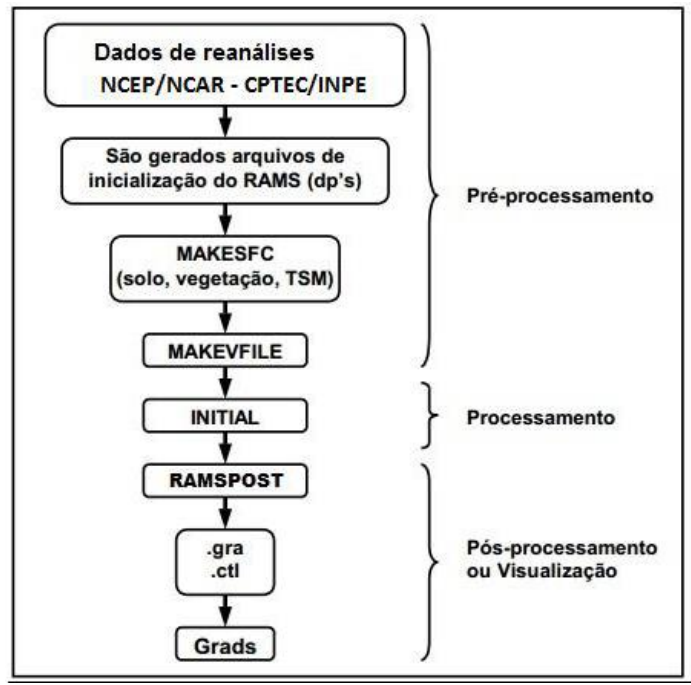

Fonte - Adaptado de Alves (2006).

A análise sinótica do período do desastre foi obtida do CPTEC/INPE e as imagens de temperatura realçada do satélite GOES - 12 .

\section{RESULTADOS E DISCUSSÃO}

Segundo Pinheiro et al. (2011), que analisaram o evento a partir dos acumulados de precipitação em estações meteorológicas do INMET convencionais (Teresópolis, Santa Maria Madalena e Teresópolis - Parque) e automáticas (Nova Friburgo e Cordeiro) da RSRJ, entre os dias 12 e 14 de janeiro de 2011, "o volume máximo foi registrado em Nova Friburgo, totalizando $209.6 \mathrm{~mm}$ ao longo do período, sendo $182.8 \mathrm{~mm}$ em apenas 24 horas" (Pinheiro et al., 2011).

A análise sinótica de superfície das $00 Z$ do dia 10 de janeiro de 2011 indica a presença de um sistema de baixa pressão de $1008 \mathrm{hPa}$, próximo ao continente, em 32S/45W. Destacam-se a formação da ZCOU e, a entrada de duas frentes frias, uma a leste $(42 S / 38 \mathrm{~W})$ e outra a oeste (48S/45W) (Figura 7a). Na carta sinótica das $00 Z$ do dia 11 de janeiro de 2011 observa-se a ZCOU já configurada, estendendo-se da Região Amazônica até o oceano Atlântico Sul. No oceano, observa-se a presença de um sistema de baixa pressão de $1004 \mathrm{hPa}$ próximo ao litoral da Região Sudeste. Este sistema acopla-se à ZCOU, transformando-a em ZCAS, nos dias seguintes (Figura 7b). Na carta das $00 Z$ do dia 12/01/2011, verifica-se uma frente fria que atua juntamente com o sistema de baixa pressão (Figura 7c). Na carta sinótica das $00 Z$ do dia 13/01/2011, observa-se a área de atuação da ZCOU sobre grande parte do Brasil, bem como o sistema de baixa pressão de $1003 \mathrm{hPa}$, atuando entre os estados do Paraná e São Paulo (Figura 7d). Na análise da carta sinótica das $00 Z$ do dia 14/01/2011, observa-se a representação da ZCAS, que se estende desde a Amazônia até o oceano Atlântico Sul. Sobre o oceano acopla-se um cavado e um centro de baixa pressão de $999 \mathrm{hPa}$, posicionado em 43S/39W (Figura 7e).

$\begin{array}{lllll}\text { Caminhos de Geografia } & \text { Uberlândia-MG } & \text { v. 21, n. } 74 & \text { Abr/2020 } & \text { p. 259-275 }\end{array}$ Página 267


Figura 7 - Carta de Superfície para os dias (a) 10/01/2011, (b) 11/01/2011, (c) 12/01/2011, (d) $13 / 01 / 2011$ e (e) 14/01/2011.

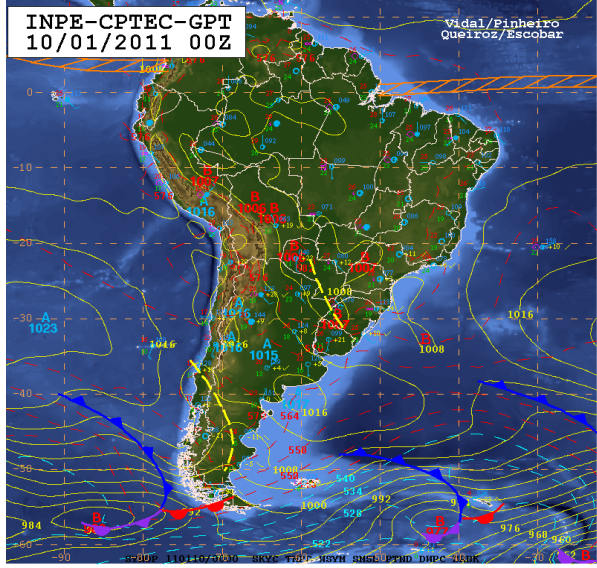

$7 a$

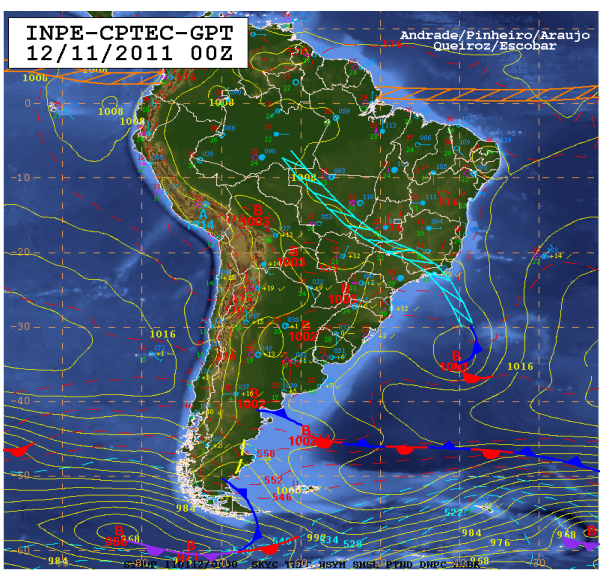

$7 c$

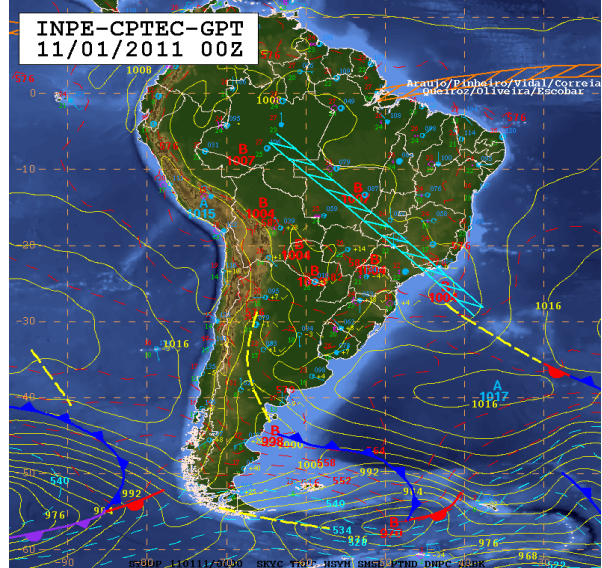

$7 b$

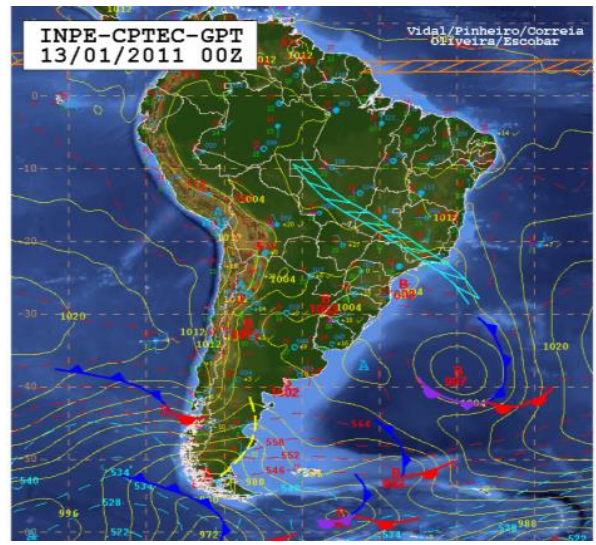

$7 d$

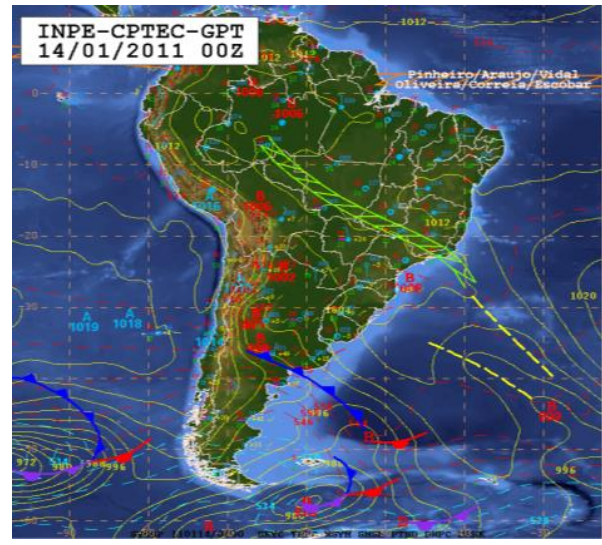

$7 \mathrm{e}$

Fonte - INPE / CPTEC (2011).

\section{IMAGENS DE SATÉLITE}

As imagens de satélites GOES - 12, canal de Temperatura Realçada, evidenciam a disponibilidade de umidade e instabilidade atmosférica no continente. As Figura 8 (a, b, c e d) confirmam a atuação da ZCOU e do sistema de baixa pressão no oceano Atlântico, nos dias 11, 12 e 13 de janeiro de 2011. A Figura 8e mostra acoplamento da ZCOU ao sistema de baixa pressão no dia 14, configurando-se na

$\begin{array}{lllll}\text { Caminhos de Geografia } & \text { Uberlândia-MG } & \text { v. 21, n. 74 } & \text { Abr/2020 } & \text { p. 259-275 Página } 268\end{array}$


Marina Aires

Simulação numérica do desastre de origem natural ocorrido em janeiro de 2011 no município de Nova Friburgo, RJ,

utilizando o modelo BRAMS

Camila Lorrana Freitas Martins Gabriela Silva Araujo Cury

Pedro José Farias Fernandes Jorge Luiz Fernandes de Oliveira

ZCAS. Esse fenômeno é caracterizado pelo transporte de umidade e calor da Região Amazônica até o Atlântico Sul.

Figura 8 - Imagens do Satélite GOES-12, canal Temperatura Realçada, para: (a) $00 Z$ de 19/01/2011, (b) $00 Z$ de 12/01/2011, (c) $00 Z$ de 11/01/2011, (d) $00 Z$ de 12/01/2011 e (e)13/01/2011.

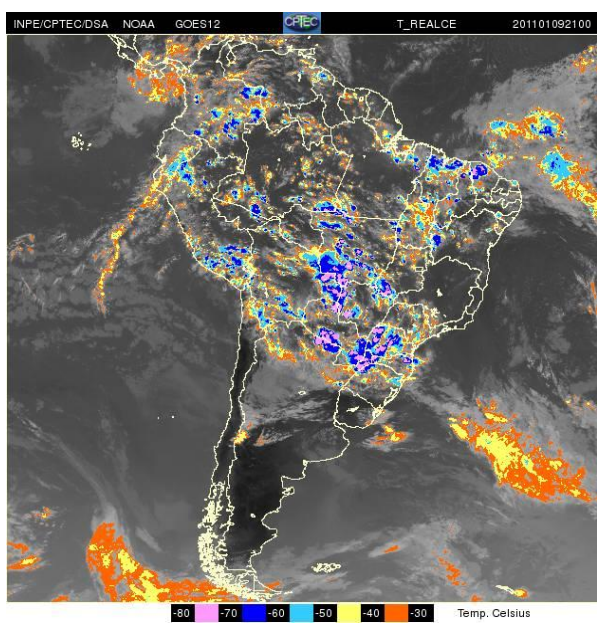

$8 a$

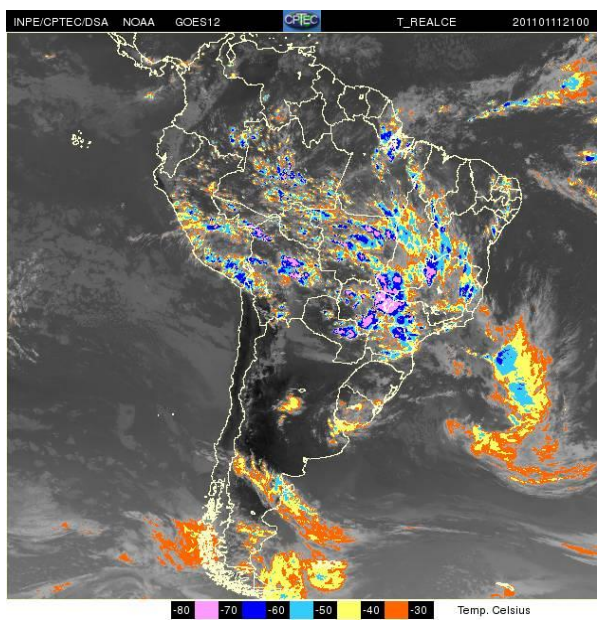

$8 \mathrm{c}$

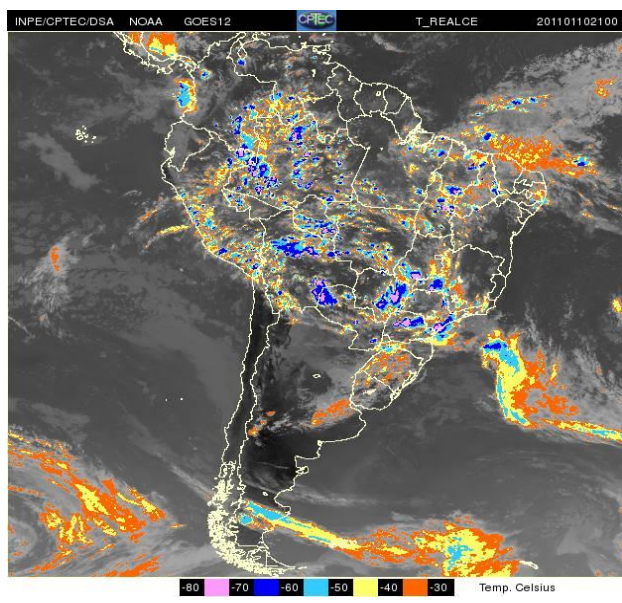

$8 b$

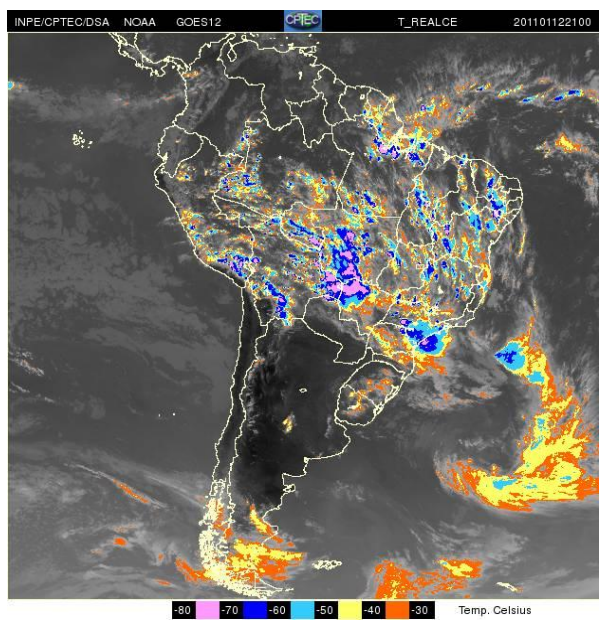

$8 d$

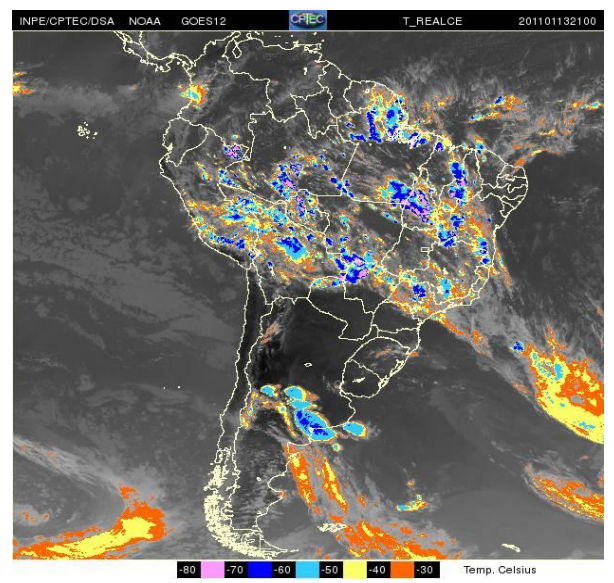

$8 e$

Fonte - CPTEC, $2011 \mathrm{~b}$. 


\section{CAMPO DE PRESSÃO OBTIDO DA R1}

As Figuras 9 (a, b, c e d) ilustram as simulações do Campo de Pressão da Reanálise 1 para $00 Z$ dos dias 11, 12, 13 e 14 de janeiro. A Figura $9 a$, referente ao dia 11 às $00 Z$, mostra um sistema de baixa pressão de $1005 \mathrm{hPa}$ no litoral Sudeste, próximo ao estado do Rio de Janeiro e a presença de outro sistema de baixa pressão próximo ao Centro-Oeste do país. Na Figura 5b, relativo ao dia 12 às $00 Z$, verifica-se que ainda não há a configuração da ZCOU em ZCAS, porém observa-se um sistema de baixa pressão de $1005 \mathrm{hPa}$ no sentido NW-SE, estendendo-se até o Atlântico. Na Figura 5c, referente ao dia 13 às $00 Z$, atuam três sistemas de baixa pressão de $1005 \mathrm{hPa}$ sobre o território brasileiro; o primeiro, próximo ao Centro-Oeste, a oeste do estado de Mato Grosso; o segundo, próximo ao estado do Paraná; e o terceiro, no Atlântico Sul. Na Figura $5 \mathrm{~d}$, dia 14 às $00 Z$, observa-se que há um sistema de baixa pressão de $1010 \mathrm{hPa}$ configurado sobre parte das regiões Nordeste e Sudeste.

Figura 9 - Campo de Pressão, para: (a) $00 Z$ de 11/01/2011, (b) $00 Z$ de 12/01/2011, (c) $00 Z$ de 13/01/2011 e (d) $00 Z$ de 14/01/2011.

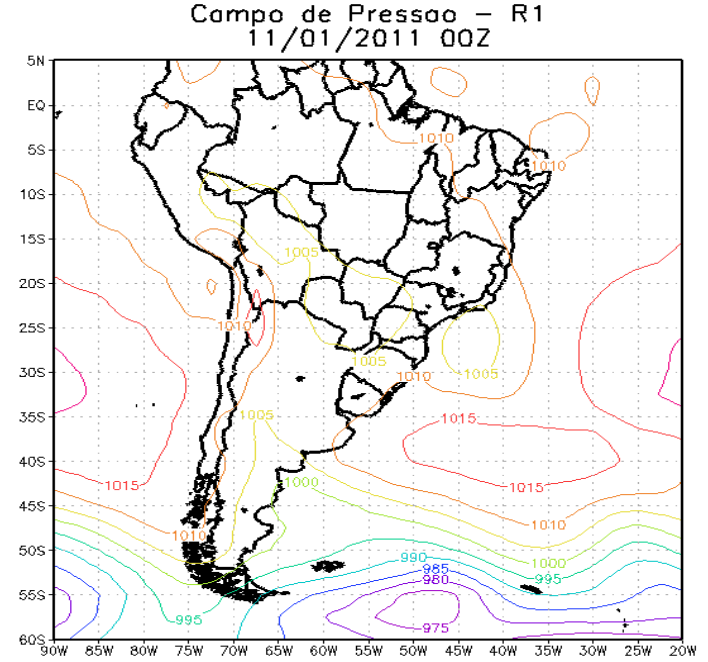

$9 a$

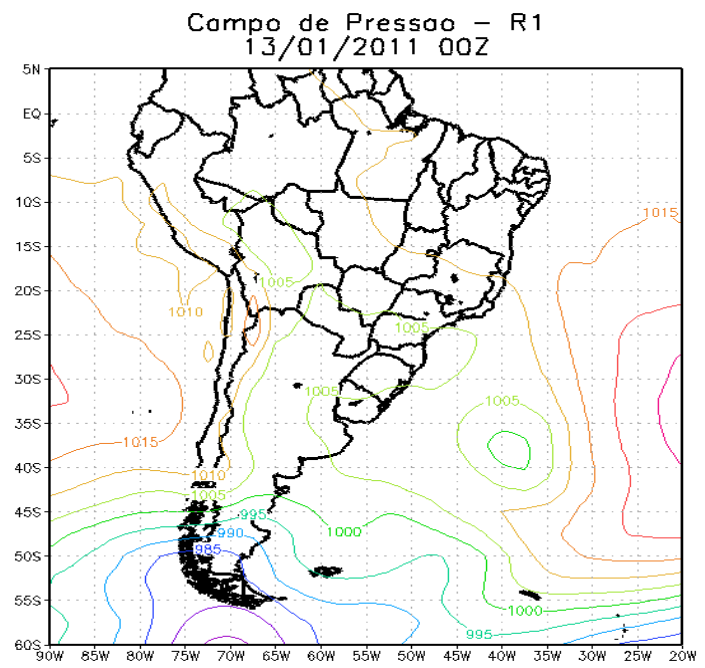

$9 c$

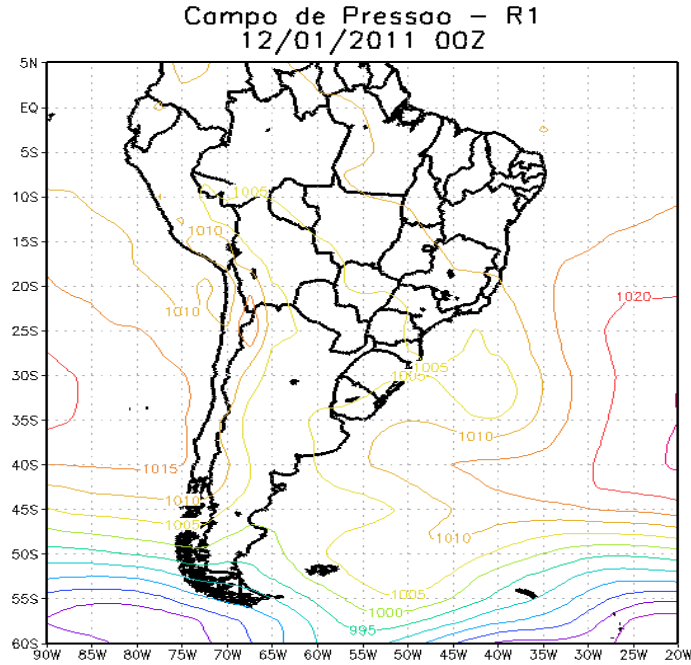

$9 b$

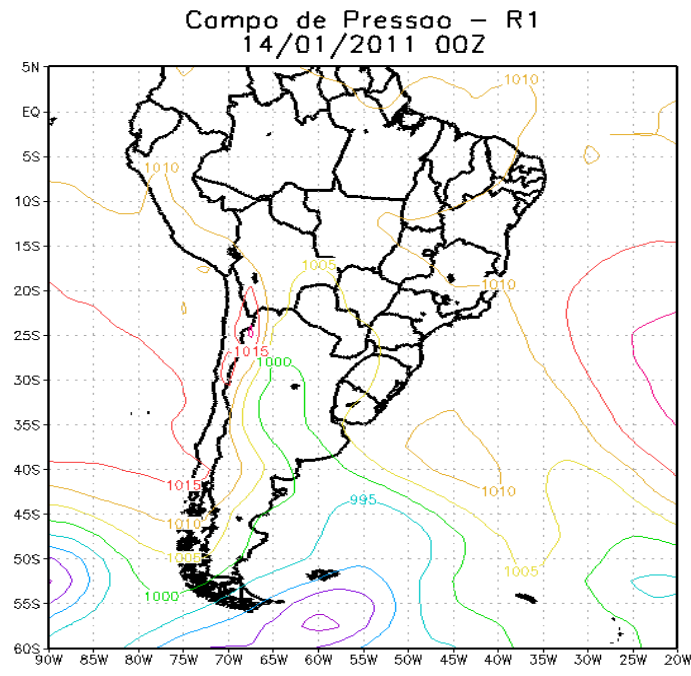

$9 d$ 


\section{CAMPO DE VENTO OBTIDO DA R1}

As Figuras 6 ( $a, b$ c e d) são os resultados das simulações de Campo de Vento, no nível de $1000 \mathrm{hPa}$, para os dias 11, 12, 12 e 14 de janeiro às 00Z. Na Figura 10a, do dia 11 às 00Z, observa-se o escoamento no sentido NW-SE estendendo-se da Amazônia até a Região Sudeste. Nota-se a presença da ZCOU, porém ainda não há a configuração da ZCAS. Na Figura 10b, do dia 12 às 00Z, verifica-se que o padrão de escoamento não está organizado no sentido NW-SE. É perceptível também o escoamento de um sistema de alta pressão próximo ao estado do Amazonas e um sistema de baixa pressão no Atlântico Sul. Na Figura 10c, do dia 13 às $00 Z$, nota-se que os ventos estão se organizando no sentido NW-SE. Observa-se também a presença de um sistema de baixa pressão no Atlântico Sul. Na Figura 10d, do dia 14 às 00Z, verifica-se o padrão do escoamento no sentido NWSE que se acopla ao sistema de baixa pressão no Atlântico, passando a se configurar como ZCAS.

Figura 10 - Campo de Vento, para: (a) $00 Z$ de 11/01/2011, (b) $00 Z$ de 12/01/2011, (c) $00 Z$ de 13/01/2011 e (d) $00 Z$ de 14/01/2011.

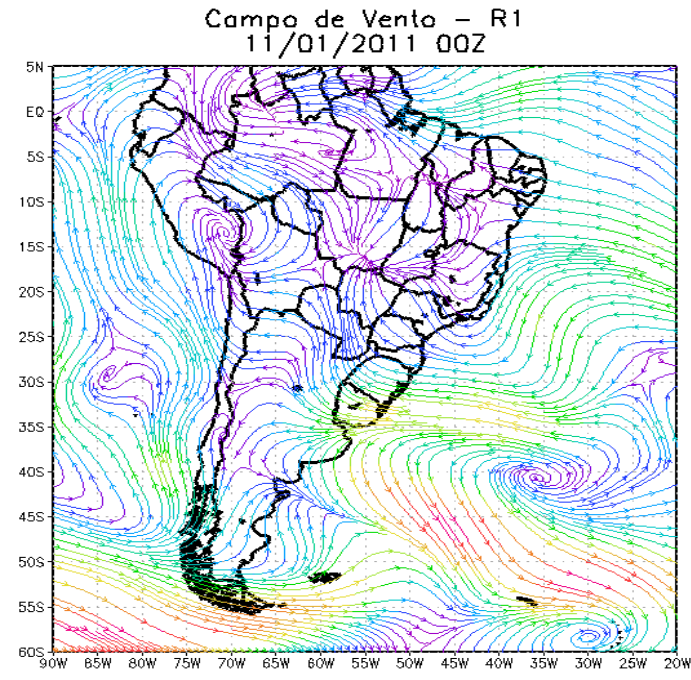

$10 a$

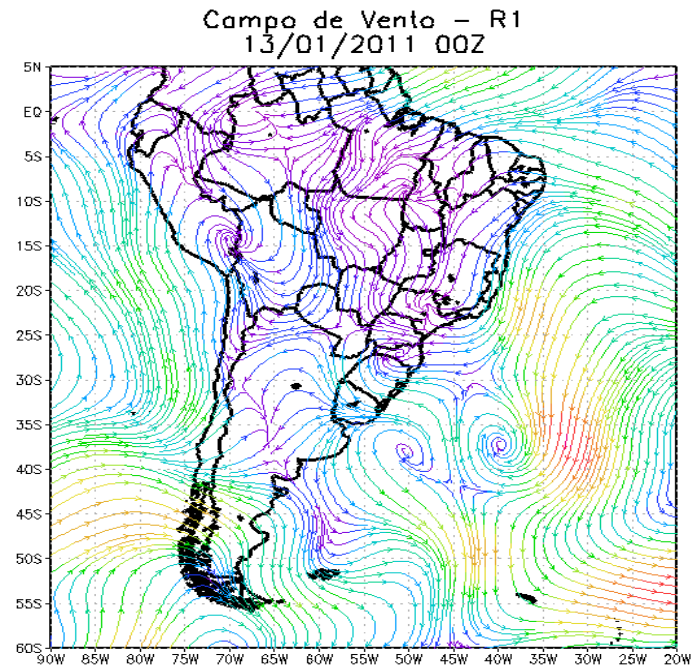

$10 \mathrm{c}$

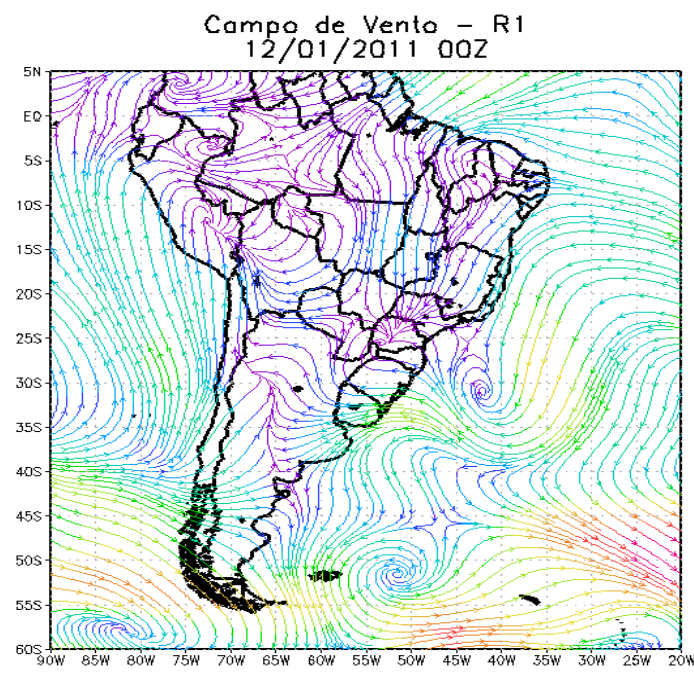

$10 b$

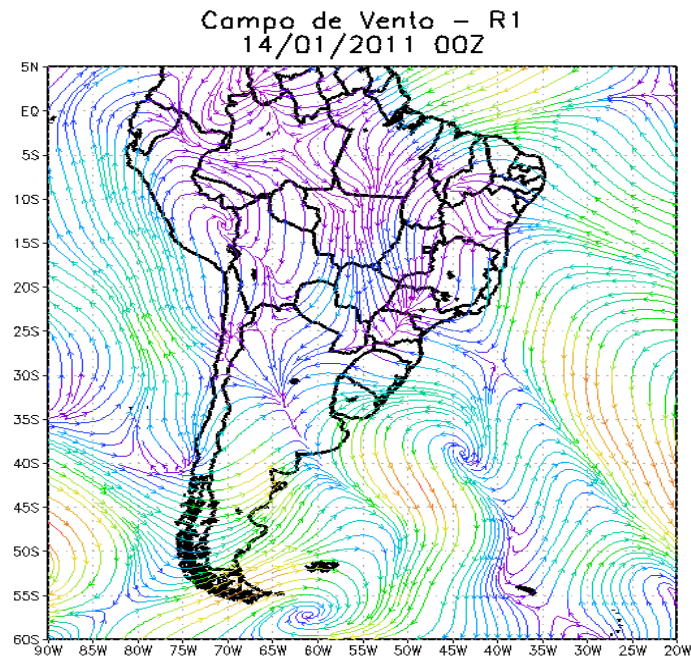

10d 


\section{UMIDADE RELATIVA E VENTO UTILIZANDO A SIMULAÇÃO DO MODELO BRAMS}

As Figuras 11 ( $a, b$ e c) são resultados das simulações dos campos de umidade relativa e vento com o BRAMS e mostram a evolução do índice de umidade e vento para o dia 12 de janeiro, data do desastre. Na simulação para o dia 12 às $00 Z$ e às 03Z, Figuras 11 a e b, observa-se que o índice de umidade relativa no município de Nova Friburgo encontra-se entre 75 e $80 \%$. Há um escoamento alinhado no sentido NW-SE. Na simulação para o dia 12 às 05Z, Figura 11c, observa-se que houve um aumento no índice de umidade para aproximadamente $85 \%$. O escoamento no sentido NW-SE mantém-se alinhado.

Figura 11 - Umidade Relativa e Campo de Vento para o dia 12/01/2011. (a) 00Z, (b) 03Z e (c) $05 Z$.

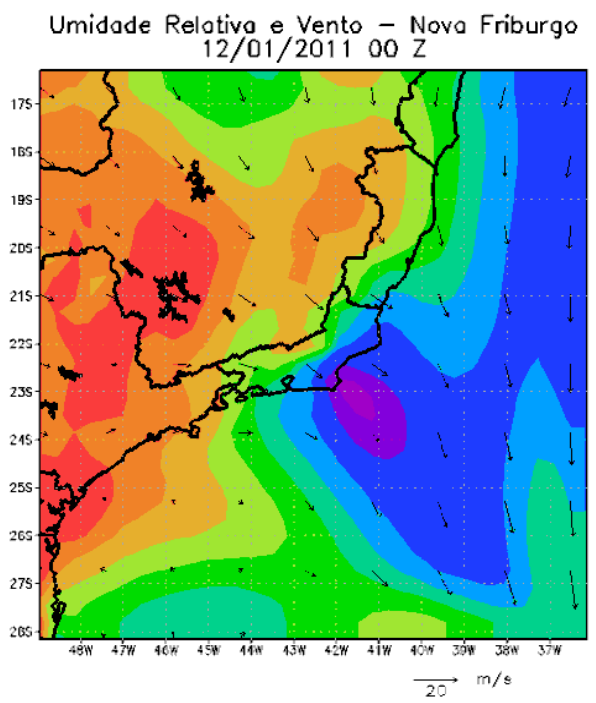

$11 \mathrm{a}$

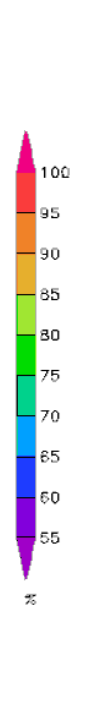

Umidade Relativa e Vento - Nova Friburgo

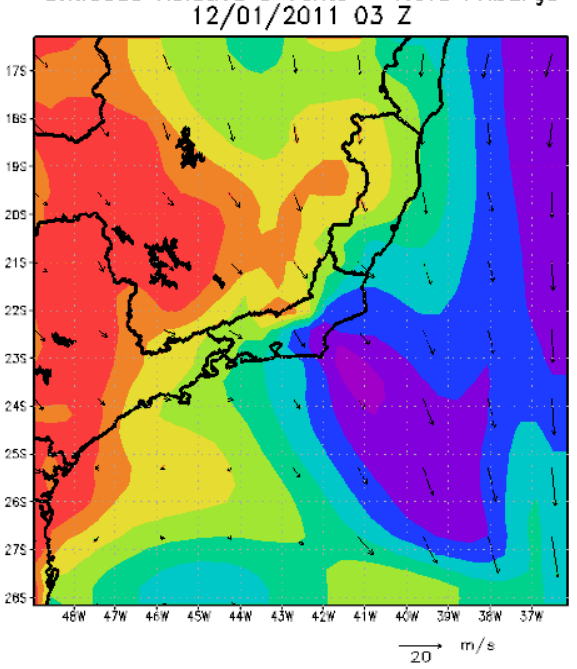

$11 \mathrm{~b}$

Umidade Relativa e Vento - Nova Friburgo $2 / 01 / 201105 \mathrm{Z}$

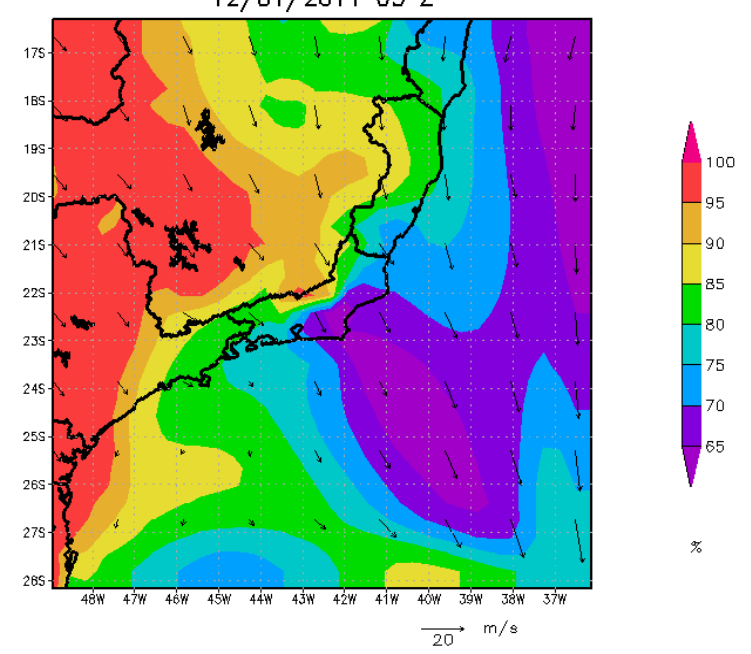

$11 \mathrm{c}$

\section{CONSIDERAÇÕES FINAIS}

O chamado "Mega desastre" na Região Serrana do Estado do Rio de Janeiro foi considerado um dos maiores desastres de origem natural que ocorreram a nível global. Um dos fatores responsáveis pela morte de pessoas e pelos prejuízos econômicos e sociais da região foi a falta de planejamento urbano nas cidades. Outra questão foi a chuva intensa, ocasionada pela atuação de áreas de instabilidade como a ZCOU, ZCAS e uma frente fria na região.

\begin{tabular}{|c|c|}
\hline Caminhos de Geografia & Uberlândia-MG \\
\hline
\end{tabular}


As cartas sinóticas de superfície e as imagens do Satélite GOES-12 caracterizaram uma atmosfera instável entre os dias 11 e 14 de janeiro. Essa instabilidade atmosférica associada à entrada de uma frente fria no estado causou fortes chuvas na Região Serrana do Rio de Janeiro. O desastre de origem natural ocorrido no município de Nova Friburgo em janeiro de 2011 foi causado pela forte instabilidade atmosférica, pelo relevo acidentado e pela ocupação irregular das encostas.

As simulações do comportamento da atmosfera com a R1, para os dias 11, 12, 13 e 14 de janeiro de 2011, mostraram que houve um escoamento de umidade e calor da região Amazônica em direção ao Sudeste. No dia 14, a forte instabilidade caracterizada pela ZCOU, acoplada a um sistema de baixa pressão no oceano, configurou a ZCAS. Observou-se que as simulações realizadas com o BRAMS geraram resultados compatíveis com os dados do CPTEC/INPE. As simulações dos campos de umidade e vento foram as que mais se aproximaram dos valores observados. As simulações da precipitação não são apresentadas no presente artigo, porque o BRAMS subestimou os resultados.

\section{AGRADECIMENTOS}

Os autores agradecem à Coordenação de Aperfeiçoamento de Pessoal de Nível Superior (CAPES) pela bolsa de doutorado concedida a um dos autores.

\section{REFERÊNCIAS}

\section{ALVES, S. C. - Avaliação do modelo de Kuo para a previsão de chuvas e tempestades}

na Região Sul do Brasil: Estudo de caso. Dissertação (Mestrado em Meteorologia), Universidade Federal de Pelotas (UFPel), 2006.

AMARAL, R.; SANTORO, J.; TOMINAGA, L.K. - Desastres Naturais: Conhecer para Prevenir. Instituto Geológico - Secretaria do Meio Ambiente, Governo do Estado de São Paulo, 2009.

BANCO MUNDIAL. Avaliação de Perdas e Danos: Inundações e Deslizamentos na Região Serrana do Rio de Janeiro. 2012.20 Disponível $<$ http://mi.gov.br/pt/c/document_library/get_file?uuid=74dde46c-544a-4bc4-a6e1852d4c09be06\&groupld=10157>. Acesso em: 21/01/2019.

CASTRO, A. L. C. Glossário de Defesa Civil - Estudo de Riscos e Medicina de Desastres. Ministério do Planejamento e Orçamento. 1998.

CEPED - Centro Universitário de Estudos e Pesquisas sobre Desastres. Atlas Brasileiro de Desastres Naturais 1991 a 2010: volume Brasil. Florianópolis: UFSC; 2012.

INPE - Instituto Nacional de Pesquisas Espaciais. CPTEC - Centro de Previsão de Tempo e Estudos Climáticos. Boletim Técnico - Cartas de Superfície 2011. . Disponível em: http://tempo.cptec.inpe.br/boletimtecnico/pt Acesso em: 13/07/2019.

. Imagens do Satélite GOES-12, canal Temperatura Realçada. Centro de Previsão de Tempo e Estudos Climáticos/Instituto Nacional de Pesquisas Espaciais. Disponível em: http://satelite.cptec.inpe.br/acervo/goes.formulario.logic Acesso em: 13/07/2019.

DANTAS, M. E., SHINZATO, E., MEDINA, A. I. M., et al. Diagnóstico Geoambiental do Estado do Rio De Janeiro. $2001 . \quad$ Disponível em <http://www.cprm.gov.br/publique/media/artigo_geoambientalRJ.pdf>. Acesso em: 21/01/2019.

DOURADO, F.; ARRAES, T.C.; SILVA, M.F. Mecanismos de Movimentos de Massa e Distribuição Espacial dos Investimentos de Reconstrução no Pós Desastre. Anuário do Instituto de Geociências - Universidade Federal do Rio de Janeiro, 2012.

DOTY, B. Grid Analysis and Display Sistem (GrADS). GrADS User's Guide. The Center for Ocean - Land- - Atmpspheric Studies (COLA) - Maryland University, USA, 1995. Disponível em: www.cola.gmu.edu/grads/gadoc/users.html Acesso em: 03/02/2020.

EMBRAPA. Empresa Brasileira de Pesquisa Agropecuária. Clima, 2001. Disponível em: http://www.cnpf.embrapa.br/pesquisa/efb/clima.htm .Acesso em: 20/07/2019. 
EM-DAT. Emergency Disaster Data Base. Consult the database - Country: Brazil, 2007. Disponível em: http://www.emdat.be. Acesso em: 20/07/2019.

GRELL, G. A., DEVENYI, D. A gereralized approach to parametrizing convection combining ensemble and data assimilation techniques. Geophysical Research Letters, Flórida, v. 29, n. 14, 2002. https://doi.org/10.1029/2002GL015311

IBGE Instituto Brasileiro de Geografia e Estatística. IBGE Cidades (2019). Disponível em: https://cidades.ibge.gov.br/brasil/ri/nova-friburgo Acesso em: 20/07/2019.

ICICT - Instituto de Comunicação e Informação Científica e Tecnológica em Saúde Observatório de Clima e Saúde; Sistema de Eventos Extremos, 2011. Disponível em: https://www.climasaude.icict.fiocruz.br/desastres/extremos/index.php. Acesso em 01/07/2019.

IESB - Instituto de Estudo Sócio Ambientais do Sul da Bahia. UFRJ - Universidade Federal do Rio de Janeiro. Projeto de Conservação e Utilização Sustentável da Diversidade Biológica Brasileira: Relatório Final do Levantamento da Cobertura Vegetal Nativa do Bioma Mata Atlântica, 2007. Disponível em: https://www.ambienteduran.eng.br/publicador/PUBLICACOES/MATA\%20ATLANTICA\%20relatorio fin al.pdf. Acesso em 20/07/2019.

INMET. Instituto Nacional de Meteorologia. Normais Climatológicas do Brasil (1961 - 1990). Disponível em http://www.inmet.gov.br/portal/index.php?r=clima/graficosClimaticos . Acesso em: 21/08/2017.

KALNAY, E. et al. The NCEP/NCAR 40 years reanalysis project. Bull Am. Meteorol. Soc. 1996. https://doi.org/10.1175/1520-0477(1996)077<0437:TNYRP>2.0.CO;2

KOBIYAMA, M.; MENDONÇA, M.; MORENO, D.A.; MARCELINO, I.P.V.O.; MARCELINO, E.V.; GONÇALVES, E.F.; BRAZETTI, L.L.P.; MOLLERI, G.S.F.; RUDORFF, F.M. Prevenção de Desastres Naturais: Conceitos Básicos. Editora Organic Trading, Curitiba, 2006.

$\mathrm{LYNCH}, \mathrm{P}$. The origins of computer weather prediction and climate modeling. Journal Computational Physics, Irlanda, Vol.: 227, pags.: 3431 - 3444, 2007. https://doi.org/10.1016/i.jcp.2007.02.034

MARCELINO, E. V. Desastres Naturais e Geotecnologias: Conceitos Básicos. Instituto Nacional de Pesquisas Espaciais. 2007.

MINISTÉRIO DA INTEGRAÇÃO NACIONAL. Anuário brasileiro de desastres naturais., Brasília, 2011.

O ESTADÃO, Catástrofe no Rio de Janeiro, 2011. Disponível em: https://internacional.estadao.com.br/blogs/olhar-sobre-o-mundo/catastrofe-no-rio-de-janeiro/. Acesso em 23/07/2019.

PALLOTTA, M.; NAKAZATO, R. Y. Caracterização de episódios de Zona de Convergência do Atlântico Sul (ZCAS) e Zona de Convergência de umidade (ZCOU) em janeiro e fevereiro de 2010. In: Congresso Brasileiro de Meteorologia, 16, 2010, Belém, Anais... Rio de Janeiro: Sociedade Brasileira de Meteorologia, 2010.

PEREIRA, F. A., PENHA, T. V., MINUZZI, R. B., LIMA, et al. - Variabilidade Climática da Precipitação em Regiões de Diferentes Altitudes no Estado do Rio de Janeiro. In: XV Simpósio Brasileiro de Geografia Física Aplicada. Anais... Vitória, Espírito Santo. 2013.

PIELKE, R.E. A three-dimensional Numerical Model off sea Breezes Over South Florida. Monthly Weather Review, Washington, Vol.: 102, p. 115 - 139, 1974.

PIELKE, R. E. A Mesoscale meteorological modeling. Orlando: Academic Press.1984. https://doi.org/10.1175/1520-0493(1974)102<0115:ATDNMO>2.0.CO;2

PINHEIRO, H.; ANDRADE, K., MOURA, C. A maior catástrofe climática do brasil sob a visão operacional do CPTEC/INPE. In: IV SIMPÓSIO INTERNACIONAL DE CLIMATOLOGIA, 4., 2011, João Pessoa-PB. Mudanças Climáticas e seus Impactos nas Áreas Urbanas. Anais.... João PessoaPB, SBMET, 2011. 
Portal G1. Chuva do dia 12 em Friburgo foi $62 \%$ maior que recorde anterior de janeiro. 2011a. Disponível em: http://g1.globo.com/brasil/noticia/2011/01/chuva-do-dia-12-em-nova-friburgo-e-maiorde-janeiro-desde-1964.html. Acesso em 23/07/2019.

PORTAL G1. ONU: deslizamento no RJ está entre os 10 piores do mundo. 2011b. Disponível em: http://g1.globo.com//brasil/noticia/2011/01/onu-deslizamento-no-rj-esta-entre-10-piores-do-mundo.html. Acesso em 04/12/2019.

PREFEITURA DE NOVA FRIBURGO. A Cidade de Nova Friburgo, 2014. Disponível em: http://novafriburgo.ri.gov.br. Acesso em 20/07/2019.

SACRAMENTO NETO, O. B.; ESCOBAR, G. C. J.; SILVA, P. E. D. Método objetivo para identificar episódios de Zonas de Convergência de Umidade (ZCOU) no ambiente operacional do Centro de Previsão de Tempo e Estados Climáticos - CPTEC. In: XVI CONGRESSO BRASILEIRO DE METEOROLOGIA, Belém-PA. Sociedade Brasileira de Meteorologia. Anais... 2010.

SOUZA, E. P. Estudo Teórico Numérico da Relação entre a Convecção e Superfícies Heterogêneas na Região Amazônica. Tese (Doutorado em Meteorologia), Universidade

de São Paulo, São Paulo, 1999.

TCE - Tribunal de Contas do Estado do Rio De Janeiro. Estudos Socioeconômicos dos Municípios do Estado do Rio de Janeiro, 2011. Disponível em: http://www.cedca.ri.gov.br/pdf/novafriburgo.pdf. Acesso em 19/04/2019.

TOBIN, G. A.; MONTZ, B. E..; HAGELMAN, R. R. Natural Hazards: Explanation and Integration. The Guilford Press, London, 2017.

TRÍPOLI, G. J., COTTON, W. R. A numerical investigation of several factors contributing to the observed variable intensity of deep convection over south Florida. Journal Applied Meteorology. v. 19, p. 1037-1063, Washington, 1980.

TRÍPOLI, G. J.; COTTON, W. R. The Colorado University Three- Dimensional Cloud/Mesoscale Model Part I: General Theorical Framword and Sensivity Experiments. https://doi.org/10.1175/15200450(1980)019<1037:ANIOSF>2.0.CO;2

Journal of Research Atmospheric, Países Baixos, v. 16, p. 185 - 220, 1982.

VILHENA, J. E. S. Influências de Friagens na Estrutura Vertical da Atmosfera da Região Amazônica: Um Estudo Numérico e Observacional. Dissertação (Mestrado em Meteorologia), Universidade Federal de Campina Grande, Paraíba, 2010.

Recebido em: 10/08/2019

Aceito para publicação em: 04/02/2020 